Original Research

\title{
Experimental Study on Removal of Iron, Manganese and Copper from Water by Microalgae
}

\author{
Meichen Wang ${ }^{1,2,3}$, Herong Gui ${ }^{2 *}$, Jiayu Chen ${ }^{2,3}$, Chen Li ${ }^{2,3}$, Chunlei Wang,3, \\ Chen Chen ${ }^{2,3}$, Chengzhou Zhao ${ }^{4}, \mathrm{Ye} \mathrm{Li}^{4}$ \\ ${ }^{1}$ School of Resources and Environmental Engineering, Hefei University of Technology, Hefei, Anhui 230009, China \\ ${ }^{2}$ National Engineering Research Center of Coal Mine Water Hazard Controlling (Suzhou University), \\ Suzhou 234000, China \\ ${ }^{3}$ School of Earth and Environment, Anhui University of Science and Technology, Huainan 232001, Anhui, China \\ ${ }^{4}$ Huaibei Mining Co. Ltd, Huaibei 235000, Anhui, China
}

Received: 5 March 2021

Accepted: 21 September 2021

\begin{abstract}
Microalgae have become popular absorption materials; therefore many studies have been conducted in order to deeply understand the metal absorption characteristics and growth rate of microalgae in water. Hence, the removal of metal elements, such as iron, manganese and copper, by four common cyanobacteria and green algae were investigated in this study. The results showed that all microalgae could grow normally, and Microcystis aeruginosa grew best. Furthermore, during the growth of microalgae, the $\mathrm{pH}$ values of the four groups gradually increased to 10 and then maintained. Different microalgae can remove iron, manganese and copper in water to some extent, while, Microcystis aeruginosa showed the best removal effect. The new observation is that with the increase of time, the treatment effect gradually becomes better, and it is the best on the 4th day. However, this study provides a scientific basis for the simultaneous treatment of microalgae culture and heavy metal polluted wastewater.
\end{abstract}

Keywords: microalgae, heavy metal removal, growth, Microcystis aeruginosa

\section{Introduction}

Water pollution is becoming more and more common, especially heavy metal pollution of wastewater, which has aroused widespread concern from all walks of life. At present, technologies such as oxidation methods [1-3],

*e-mail: guiherong@163.com adsorption methods [4-6], and membrane treatment methods [7] are commonly used for wastewater polluted by heavy metals, but these technologies generally have limitations such as high cost and low efficiency and are not suitable for wastewater with a low concentration of heavy metals [8].

In recent years, many scholars have studied the removal of metal elements from water by microalgae. Cynthia et al. [9] have biologically treated 
heavy metals in mine tailings water and found that the removal rates of copper $(\mathrm{Cu})$ and $\mathrm{Mo}$ in mine tailings water by microalgae are $64.7 \%$ and $99.9 \%$, respectively. Compared with the control group, the cell morphology of microalgae exposed to mine tailings water will change, showing higher protein content and lipid content. Rosario et al. [10] took copper in acid mine water as the research object, and confirmed the same result. It was also found that cell density, growth rate and lipid content decreased with the increase of $\mathrm{Cu}$ concentration. Wang et al. [11] took Microcystis aeruginosa as the research object, and explored the absorption and purification kinetics of potential inorganic arsenic in phosphorusrich and phosphorus-deficient environments through long-term and short-term experiments. Previous reports found that the enrichment and purification of arsenic by living algae are not only affected by arsenic forms, but also by the concentration of phosphate in the surrounding environment. Brinza et al. [12] studied the adsorption capacity and mechanism of zinc by microalgae collected along the Baltic Sea coast under different conditions, mainly considering the influencing factors such as microalgae dosage, zinc source and algae collection time. The adsorption mechanism has been studied by various methods, and it is proved that Fucus is a potential adsorption material, which can be used for zinc adsorption in wastewater from mining and electroplating industries.

Qiu et al. [13] compared the effects of different kinds of iron on the growth of Anabaena flos-aquae, and found that the promotion of iron species on algae growth was in the order of ferric ammonium citrate $>$ EDTA-Fe $>$ iron ions $>$ iron oxalate. Deng et al. [14] studied the physiological response and accumulation ability of Microcystis aeruginosa to zinc and cadmium and thought that Microcystis aeruginosa had considerable remediation potential for freshwater lakes with a low concentration of heavy metals. Ling et al. [15] organically combined microalgae culture with sewage treatment and found that Scenedesmus obliquus can remove more than $99 \%$ of nitrogen and phosphorus, and can make it accumulate more lipid and biomass. Wu et al. [16] discussed the effect of microplastics on the photosynthetic system of Chlorella pyrenoidosa, and the results showed that microplastics had a negative effect on the concentration of chlorophyll-a in microalgae.

However, a large number of literatures only focus on the removal of single metal element by microalgae. There are few studies on microalgae growth and removal of various metal elements at the same time. Therefore, we chose four kinds of microalgae which are easy to obtain, have economic value and are widely used for research. In this study, we chose the common over-standard elements $(\mathrm{Mn}, \mathrm{Fe}, \mathrm{Cu})$ in groundwater as the removal objects. Then, we inferred the reasons for the growth differences of microalgae in the experiment, and provided new ideas and insights for the biological removal of metal elements and the proliferation and growth of microalgae.

\section{Materials and Methods}

\section{Experimental Microalgae}

Microalgae are widely distributed in the biosphere, and there are many kinds. In this study, four common algae, Anabaena flos-aquae, Microcystis aeruginosa, Scenedesmus obliquus, and Chlorella pyrenoidosa, were selected as experimental algae species. The algae species used in the experiment were all from the Institute of Hydrobiology, Chinese Academy of Sciences.

Anabaena flos-aquae is a species of cyanophyta prokaryote, which grows mostly in freshwater or wetlands, and has a long filament shape. Anabaena flosaquae is composed of vegetative cells, idioblast, and thick-walled spores. The vegetative cells can carry out photosynthesis similar to that of higher plants. Nitrogen fixation can be carried out by nitrogenase contained in idioblast, and $\mathrm{N}_{2}$ in the air can be converted into $\mathrm{NH}_{3}$ or $\mathrm{NH}_{4}^{+}$for algae to use.

Microcystis aeruginosa is the typical prokaryotic unicellular organism of Cyanophyta. There are no organelles in the cells, and the protoplasm contains pigments such as chlorophyll-a, carotene, and phycholin [17]. The population of Microcystis aeruginosa are usually lumpy and irregularly reticulated, and a single Microcystis aeruginosa are spherical. Microcystis aeruginosa mainly grow in freshwater areas with high organic matter content such as lakes and ponds. It is the dominant population of most cyanobacteria blooms in the world and one of the most common cyanobacteria in China [11, 17].

Scenedesmus obliquus is common single-celled green algae, which widely exists in freshwater bodies such as ponds and lakes. Scenedesmus obliquus has strong adaptability and simple requirements for a growth environment and can utilize nutrients such as nitrogen and phosphorus to propagate rapidly.

Chlorella pyrenoidosa is a unicellular eukaryote and a lower plant, belonging to the Chlorella phylum. Chlorella pyrenoidosa is spherical or oval, widely distributed, fast-growing, and easy to be cultivated artificially [18]. Chlorella pyrenoidosa has a simple structure and is sensitive to the external environment, so it is also used in related fields such as the environment.

\section{Experimental Conditions}

In order to reduce the interference of foreign bacteria from the external environment, all operations in this study were carried out on a clean bench. In order to avoid the interference of other elements from glassware (conical flask, beaker, measuring cylinder, etc.), all glassware used in this experiment were soaked in $5 \%$ dilute $\mathrm{HNO}_{3}$ for more than $12 \mathrm{~h}$. The equipment was rinsed with clean water three times, put it in an autoclave for sterilization at $121^{\circ} \mathrm{C}$ for $30 \mathrm{~min}$, and then cooled to room temperature on a clean workbench. 

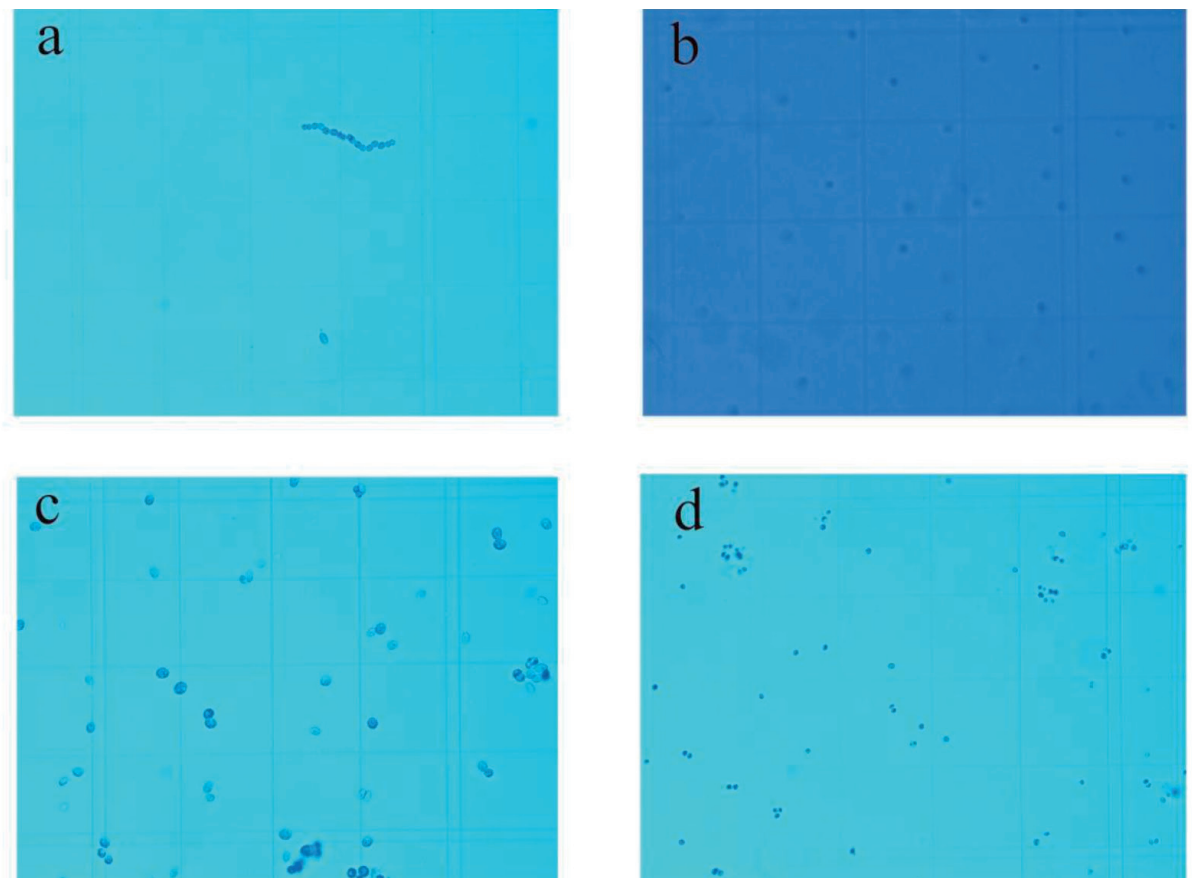

Fig. 1. Microalgae under microscope (a: Anabaena flos-aquae;b: Microcystis aeruginosa;c: Scenedesmus obliquus;d: Chlorella pyrenoidosa).

In this study, all algae were cultured in a light incubator, with the following parameters: temperature $25^{\circ} \mathrm{C}$, light intensity $3500 \mathrm{Lx}$, light and dark period $12 \mathrm{~h} / 12 \mathrm{~h}$. To avoid having algae settling and attaching on the walls of the conical flasks, and to avoid uneven illumination due to static positioning, the conical flasks were shaken regularly every day and the position of the conical flasks were changed randomly to ensure the normal and uniform growth of microalgae in each conical flask.

\section{Experimental Process}

(1) Seed conservation: four microalgae, namely Anabaena flos-aquae, Microcystis aeruginosa, Scenedesmus obliquus, and Chlorella pyrenoidosa, were inoculated into the newly prepared BG11 culture medium and placed in a light incubator for culturing. After the microalgae reached normal growth stage, the formal experiment began.

(2) Inoculation: an adequate amount of algae solution was removed for seed preservation. The sample was centrifuged and the supernatant was discarded. Sterile ultrapure water was added to rinse the algae three times, and then the algae were transfer to an experimental solution. All experiment groups were conducted in parallel. The inoculated algae solutions were placed in a $3500 \mathrm{Lx}$ illumination incubator at $25^{\circ} \mathrm{C}$, and the illumination period was adjusted to $1: 1$, that is, $12 \mathrm{~h}$ illumination and $12 \mathrm{~h}$ darkness.

(3) Testing: The four types of algae solution were sampled at fixed time points every day, and the samples were tested for various parameters.
All the above operations were carried out in an aseptic environment.

\section{Analytical Methods}

The $\mathrm{OD}_{680}$ and chlorophyll of microalgae were determined by Ultraviolet-visible Spectrophotometer (MAPADA 722S, Shanghai, China). The $\mathrm{pH}$ of water body is measured by $\mathrm{pH}$ meter (PHS-3E, Shanghai, $\mathrm{China}) . \mathrm{Fe}, \mathrm{Mn}$ and $\mathrm{Cu}$ concentration in the water phase were determined using inductively coupled plasmamass spectrometer (7500a, Agilent Technologies Inc., California, United States of America).

\section{Statistical Analysis}

All experiments were independently repeated three times, and data were recorded as means with their corresponding standard deviations (SD). SPSS 12.0 was used to perform statistical analysis on the data. Graphics were generated using Origin Pro 2019.

\section{Results and Discussion}

\section{Algae Growth Characterization}

If algae grow in the same environment they have the same growth conditions but use resources differently. Zerveas et al. [19] studied the survival strategy of microalgae in a closed system with anoxic environment and the possibility of creating an oxygenic atmosphere through the photosynthetic management 


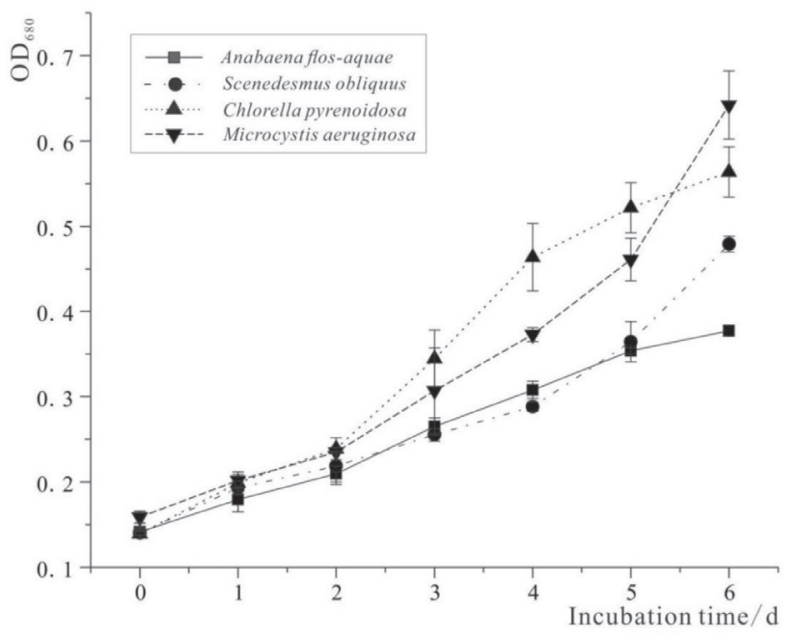

Fig. 2. Growth curves of different microalgae with time.

of solar radiation. Yooeun et al. [20] studied the effects of foamed polystyrene leachate on photosynthesis of four microalgae, which showed different sensitivities and changing trends.

With the absorbance $\left(\mathrm{OD}_{680}\right)$ of algae solution as ordinate and culture days as abscissa, the growth curves of four microalgae were drawn. As shown in Fig. 2, the growth curves of the four microalgae all increased within 0-6 days of the experiment, that is, the optical density of the four microalgae all increased with the increase of culture time. In the early growth stage, because the four microalgae were just inoculated into the new environment and did not multiply in large numbers immediately, the growth of $\mathrm{OD}_{680}$ was slow. When microalgae adapted to the new environment, the metabolic activity of cells was stable, the enzyme system was improved, and the growth rate of $\mathrm{OD}_{680}$ became larger. It can be seen from the figure that at the end of the experiment ( $t=6 \mathrm{~d}$ ), the optical density of the four microalgae is Microcystis aeruginosa $>$ Chlorella pyrenoidosa $>$ Scenedesmus obliquus $>$ Anabaena flosaquae.

Although the growth laws of the four microalgae were the same during the experiment, there were still differences in the growth rates among the four microalgae due to different microalgae species and different requirements for the external environment. It can be seen from Fig. 3 that the growth rate of microalgae changed in real-time, that is, the growth rate of the same microalgae were different in different periods, and the growth rate of different microalgae in the same period was also different. The growth rate distribution of microalgae was different, among which the growth rates of Anabaena flos-aquae and Chlorella pyrenoidosa reached the maximum in the middle of the experiment, while the growth rates of Scenedesmus obliquus and Microcystis aeruginosa reached the maximum at the end of the experiment. The maximum growth rate of the four microalgae showed two different laws, which were mainly caused by different microalgae species, different sensitivity to the external environment, and different reaction speeds.

\section{Characterization of Organic Matter}

With the increase of culture time and the growth of microalgae, the content of organic matter (such as $\mathrm{UV}_{254}$, chlorophyll, etc.) in algae solution was gradually increasing. Monitoring organic matter in algae solution

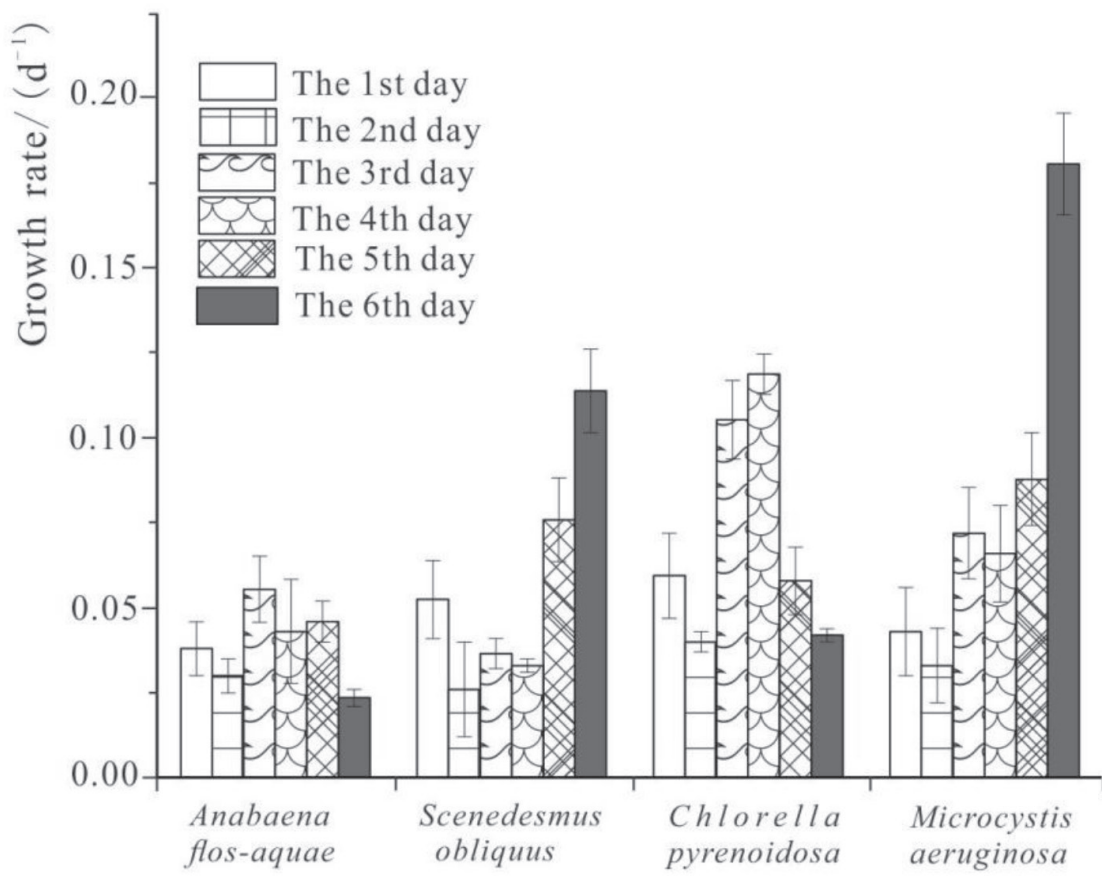

Fig. 3. Growth rate diagram of different microalgae with time. 


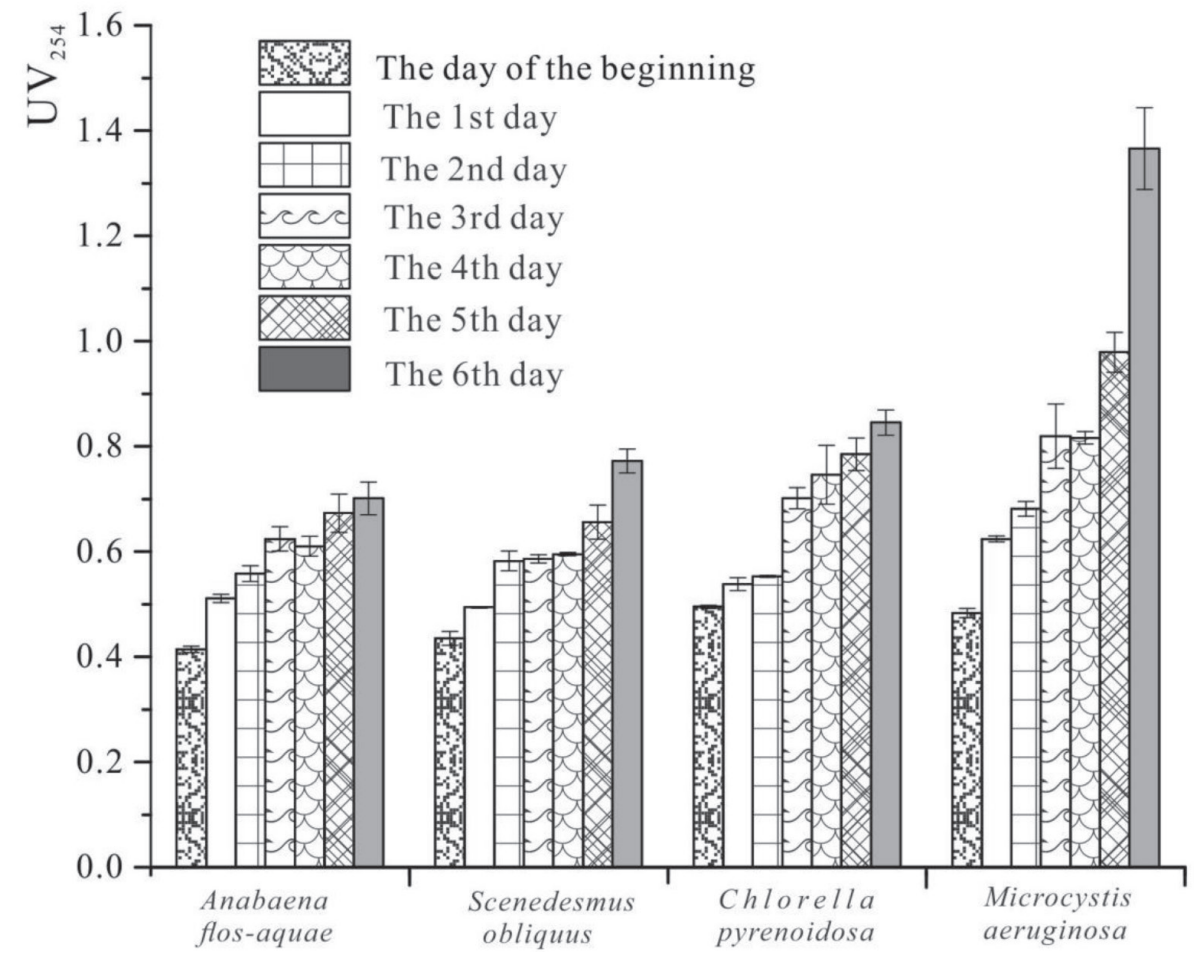

Fig. 4. $\mathrm{UV}_{254}$ changes in different microalgae growth processes.

can not only reflect the content of organic matter in algae solution but also reflect the growing trend of microalgae.

It can be seen from Fig. 4. that $\mathrm{UV}_{254}$ of the four microalgae increased with the increase of culture time, indicating that the longer the culture time, the more organic matter content in algae solution. The increase of $\mathrm{UV}_{254}$ in the algae solutions was likely due to the growth of active microalgae and increases in their biomass. On the other hand, microalgae secrete and metabolize some organic substances during their growth.

Chlorophyll can effectively reflect the biomass and nutritional status of microalgae [21]. The relationship between chlorophyll content and culture time was plotted with culture time as abscissa and chlorophyll content of algae solution as ordinate. It can be seen from Fig. 5 that the chlorophyll content of microalgae increases with the increase of culture time, which may be related to the increase of microalgae abundance and biomass. The chlorophyll content of Anabaena flos-aquae, Scenedesmus obliquus, and Microcystis aeruginosa all reached the maximum specific increase on the second day, which were $125.9 \%, 114.4 \%$, and $102.6 \%$, respectively. Chlorella pyrenoidosa reached the maximum specific increase of $89.7 \%$ on the first day.

Because the four microalgae were growing all the time and the biomass was accumulating, the chlorophyll content of the four microalgae reached the maximum at the end of the experiment. However, microalgae have abundant nutrition in the new environment, and algae rapidly synthesize a large amount of chlorophyll. However, due to the increase of algae, lack of nutrients, and competition among microalgae, chlorophyll continued to increase, but the increase rate decreased, so the maximum specific increase of the four microalgae appeared in the early stage of the experiment.

\section{Change of $\mathrm{pH}$ Value}

The $\mathrm{pH}$ changes of four microalgae treated aqueous solutions during algae growth were shown in Fig. 6. The law of $\mathrm{pH}$ in each experimental group was the same, which increased gradually with the increase of culture time and tended to be stable at $\mathrm{pH}=10$. There were similar phenomena and laws in the research of other scholars. Han et al. [22] used Chlorella pyrenoidosa to carry out lipid productivity experiment, and found that the $\mathrm{pH}$ of algae solution increased rapidly from 7.8 to fluctuate around 9.5; Andeden et al. [23] compared the effects of different $\mathrm{pH}$ treatments on the content, growth and biochemical composition of triacylglycerol (TAG) of auxin (Auxenochlorella protoecoides KP7) in Leguminosae, and found that $\mathrm{pH}$ had certain effects on TAG, starch and chlorophyll.

The $\mathrm{pH}$ of water is an important ecological factor of the environment of aquatic microalgae ecological environment, which mainly affects the growth and metabolism of algae from three aspects: the availability of $\mathrm{CO}_{2}$, the utilization efficiency of inorganic carbon source, and the permeability of cell membrane [24], and can also reflect the growth state of microalgae and the utilization of carbon source in algae solution. Inorganic carbon in water mainly exists in four forms: $\mathrm{CO}_{2}$, $\mathrm{H}_{2} \mathrm{CO}_{3}, \mathrm{HCO}_{3}^{-}$and $\mathrm{CO}_{3}{ }^{2-}$, with the following balance: 


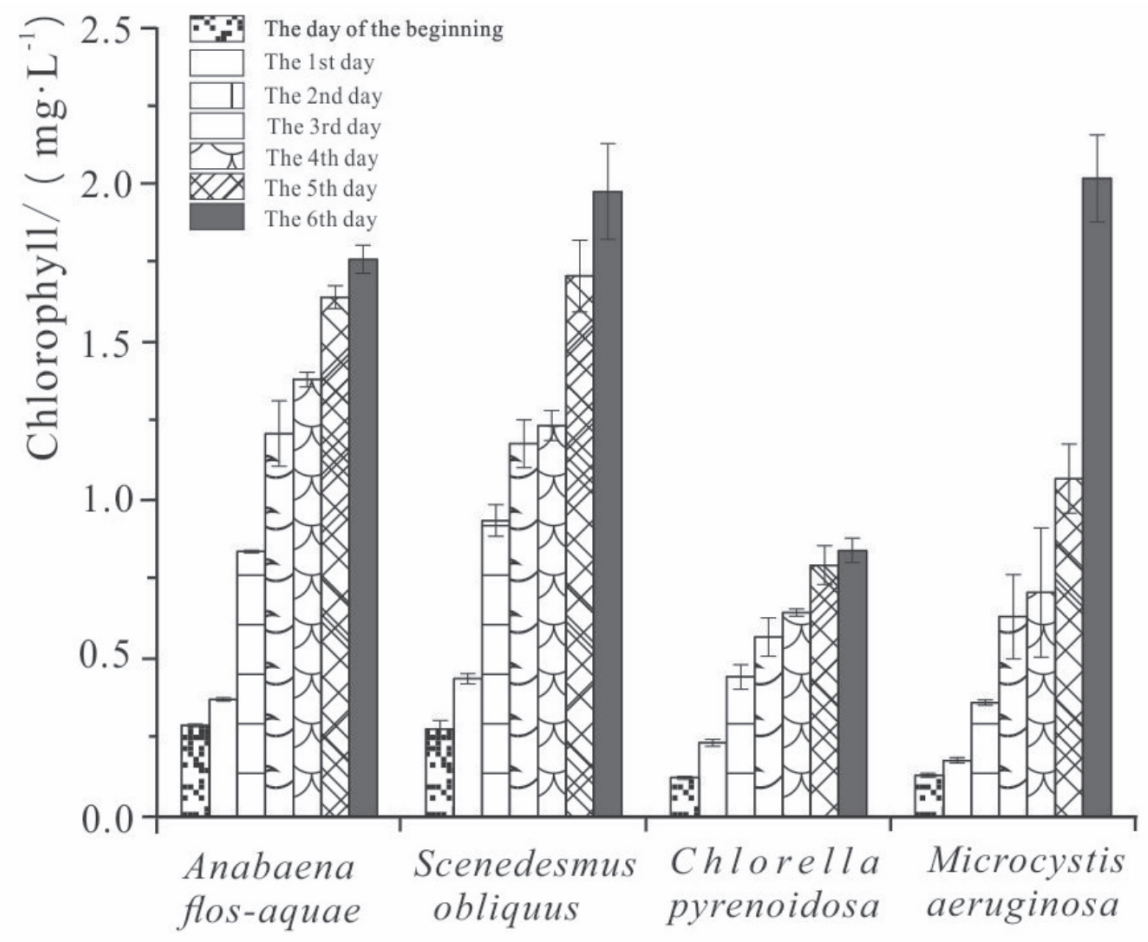

Fig. 5. Changes of chlorophyll content during the growth of different microalgae.

$$
\mathrm{CO}_{2}+\mathrm{H}_{2} \mathrm{O}=\mathrm{H}_{2} \mathrm{CO}_{3}=\mathrm{H}^{+}+\mathrm{HCO}_{3}^{-}=2 \mathrm{H}^{+}+\mathrm{CO}_{3}^{2-}
$$

At the early stage of the experiment, the four microalgae entered a suitable new environment, and their photosynthesis was greater than respiration, which consumed a lot of $\mathrm{CO}_{2}$ dissolved in algae solution and destroyed the balance mode of inorganic carbon in water, so the $\mathrm{pH}$ of algae solution gradually increased. In the later stage of the experiment, due to the limited photosynthetic capacity and strong $\mathrm{pH}$ adjustment ability of microalgae [25], the $\mathrm{pH}$ of the algae solution gradually stabilized after increasing to 10 .

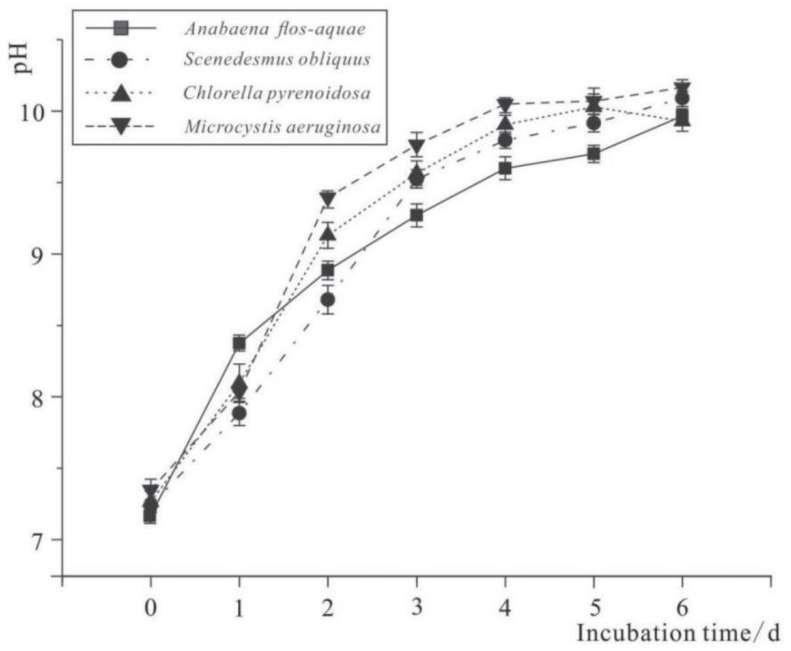

Fig. 6. Changes of $\mathrm{pH}$ during the growth of different microalgae.

\section{Removal of Iron and Manganese}

$\mathrm{Fe}$ and $\mathrm{Mn}$ are essential trace elements in the growth process of microalgae and play an important role in photosynthesis, respiration, nitrogen fixation, and other life activities [26]. Fe is a cofactor of many enzyme systems and an indispensable component of cytochrome and iron redox protein [27]; $\mathrm{Mn}$ is a component and activator in response to enzymes and coenzymes and has a detoxification effect on oxides produced by respiration. The microalgae used the $\mathrm{Fe}$ and $\mathrm{Mn}$ elements in water to grow. At the same time, bioremediation of heavy metals in the water environment occurred through microalgae growth.

Domestic and foreign researchers have done a lot of research on the adsorption and removal of heavy metals by microalgae [28]. The adsorption mechanism was very complex and there were many influencing factors. In this paper, only the species of microalgae were changed, and the growth of different microalgae were observed. The removal of iron and manganese from the water was observed and monitored in order to determine rules for the removal of these trace elements from water by the four types of microalgae.

According to the limits of iron $(\leq 300 \mu \mathrm{g} / \mathrm{L})$ and manganese $(\leq 100 \mu \mathrm{g} / \mathrm{L})$ in the Hygienic Standard for Drinking Water (GB5749-2006), the concentrations of iron and manganese in this study were set at $350 \mu \mathrm{g} / \mathrm{L}$ and $150 \mu \mathrm{g} / \mathrm{L}$, respectively.

It can be seen from Fig. 7 that the change of iron content in the four groups of experiments decreased first and then increased. The time for different microalgae to reach the maximum removal rate was different, 

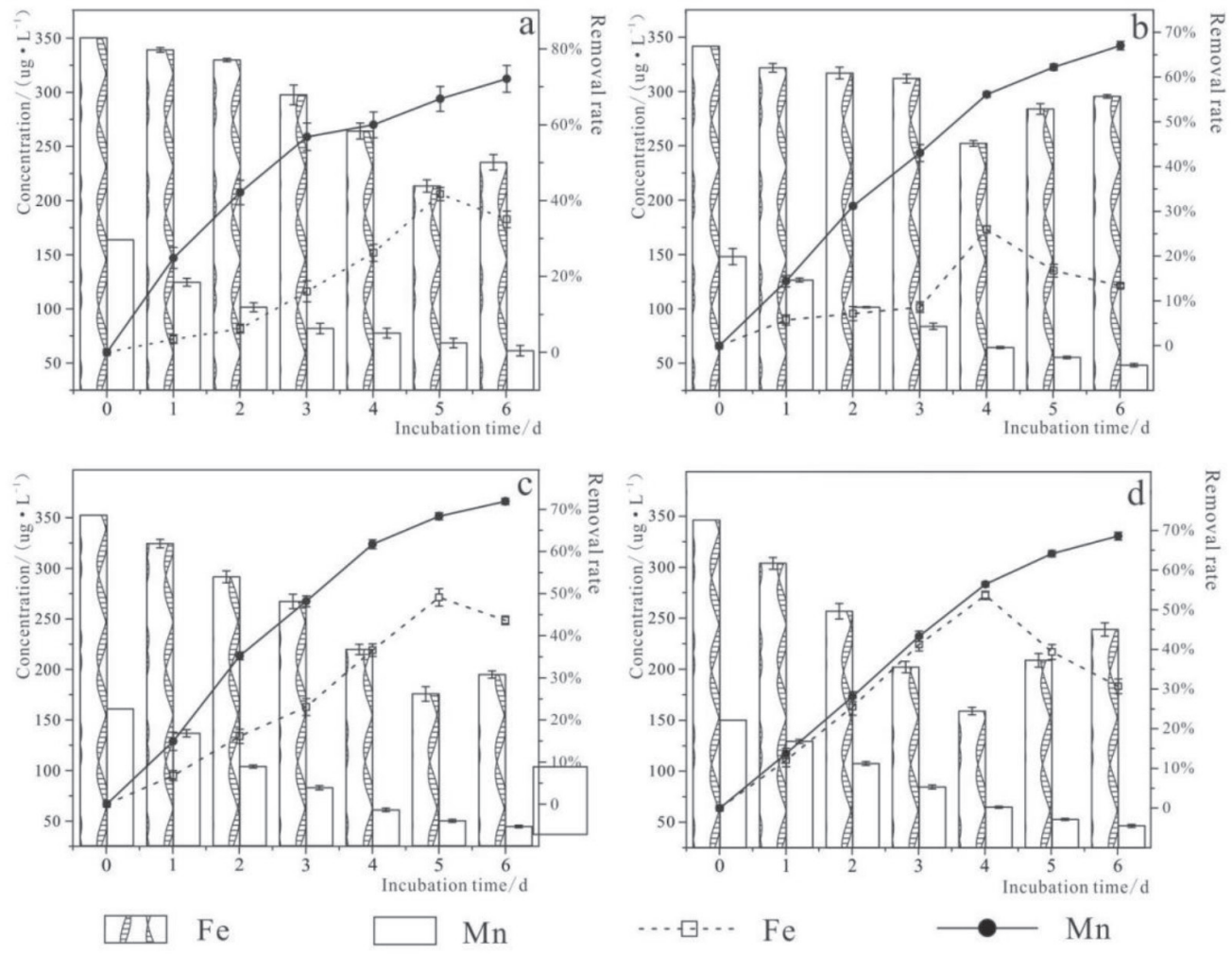

Fig. 7. Effects of different microalgae on the removal of Fe and Mn: a) Anabaena flos-aquae, b) Scenedesmus obliquus, c) Chlorella pyrenoidosa, d) Microcystis aeruginosa.

among which Scenedesmus obliquus and Microcystis aeruginosa reached the maximum value on the fourth day, which were $26.21 \%$ and $54.13 \%$ respectively; Anabaena flos-aquae and Chlorella pyrenoidosa reached their maximum values on the fifth day, which were $42.09 \%$ and $49.64 \%$, respectively.

In the four groups of experiments, the Mn content gradually decreased and the removal rate gradually increased. The maximum removal rates of the four microalgae reached the $6^{\text {th }}$ day, and the maximum removal rates of Anabaena flos-aquae, Scenedesmus obliquus, Chlorella pyrenoidosa, and Microcystis aeruginosa were $72.71 \%, 67.58 \%, 72.68 \%$, and $69.21 \%$, respectively.

The removal rates of $\mathrm{Fe}$ and $\mathrm{Mn}$ by four microalgae were different. Among them, the removal rate of $\mathrm{Fe}$ by Anabaena flos-aquae, Scenedesmus obliquus and Chlorella pyrenoidosa was much lower than that of $\mathrm{Mn}$. However, the removal rate of Fe by Microcystis aeruginosa was almost the same as that of $\mathrm{Mn}$ in the early stage of the experiment, but there was a big difference in the later stage of the experiment. It may be

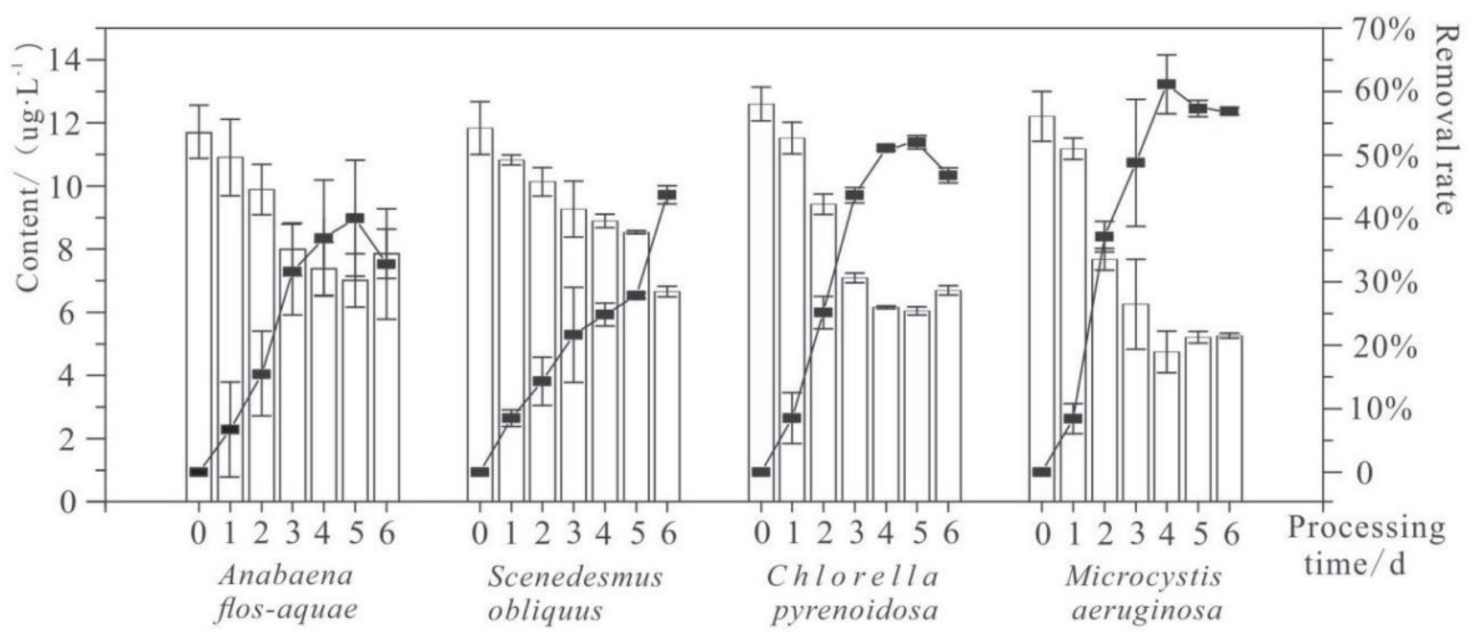

Fig. 8. Effects of different microalgae on the removal of $\mathrm{Cu}$. 
because microalgae show different affinities to $\mathrm{Fe}$ and $\mathrm{Mn}$ in different periods, and their demands for $\mathrm{Fe}$ and Mn were different, so the removal rates were different. The maximum removal rate of $\mathrm{Fe}$ was $54.13 \%$, which appeared on the fourth day of Microcystis aeruginosa treatment group. The maximum removal rate of $\mathrm{Mn}$ was $72.71 \%$, which appeared on the 6th day of Anabaena flos-aquae treatment group.

\section{Removal of Trace Copper}

Brinza et al. [29] found that algae can not only adsorb and remove specific metal ions but also synchronously remove various metal ions, such as $\mathrm{Ca}, \mathrm{Cd}, \mathrm{Cu}, \mathrm{Pb}$, etc. Monteiro et al. [30] think that when the pollution degree of heavy metals is low, the traditional physical and chemical methods are costly and ineffective, and the microbial method is an efficient, economical, and feasible new way. In this study, it was found that the four microalgae not only have a good removal effect on higher concentrations of $\mathrm{Fe}$ and $\mathrm{Mn}$ but also have a good removal effect on lower concentrations of $\mathrm{Cu}$.

Four microalgae showed two different removal rules, and the removal rate of $\mathrm{Cu}$ by Scenedesmus obliquus increased with the increase of treatment time. The removal rates of Anabaena flos-aquae, Chlorella pyrenoidosa, and Microcystis aeruginosa for $\mathrm{Cu}$ increased first and then decreased with time, among which the removal rates of Anabaena flos-aquae and Chlorella pyrenoidosa reached the maximum on the 5th day, while that of Microcystis aeruginosa reached the maximum on the $4^{\text {th }}$ day, and the maximum removal rate of Microcystis aeruginosa (61.13\%) was much higher than the other three groups.

Different microalgae have obvious differences in $\mathrm{Cu}$ removal ability, which mainly depends on the structure of algae cells, the types, and quantities of related groups [31]. The law of $\mathrm{Cu}$ removal by Scenedesmus obliquus was different from that of the other three microalgae. The analysis suggests that there were many related genes in Scenedesmus obliquus, and the groups were not saturated during the whole experiment, so the removal rate of the experimental group increases with time. When the removal rates of Anbaena flos-aquae, Chlorella pyrenoidosa, and Microcystis aeruginosa reached the maximum, the related groups reached saturation, and the $\mathrm{Cu}$ in algae was released into the water environment, and the $\mathrm{Cu}$ content in the water increased, so the $\mathrm{Cu}$ removal rate decreased in the later stage. There were differences in the structure and properties of different microalgae, so the maximum removal rate of each microalga and the time to reach the maximum removal rate are different.

Considering the removal rate of $\mathrm{Fe}, \mathrm{Mn}$, and $\mathrm{Cu}$, the growth of microalgae, and the length of treatment time, it is considered that Microcystis aeruginosa was the dominant algae species in this experiment, and the treatment effect was best when the treatment time is
4 days. According to the results of this study, we can culture Microcystis aeruginosa in wastewater with low concentration of $\mathrm{Fe}, \mathrm{Mn}$ and $\mathrm{Cu}$. On the one hand, we can obtain Microcystis aeruginosa with economic value, on the other hand, we can remove low-concentration Fe, $\mathrm{Mn}$ and $\mathrm{Cu}$ from wastewater. It provides new ideas for the cultivation of microalgae and the treatment of heavy metal wastewater.

\section{Conclusions}

(1) The four microalgae can grow normally, and the growth order is Microcystis aeruginosa $>$ Chlorella pyrenoidosa $>$ Scenedesmus obliquus $>$ Anabaena flosaquae. The growth rate of Anabaena flos-aquae and Chlorella pyrenoidosa reached the maximum in the middle of the experiment, while Scenedesmus obliquus and Microcystis aeruginosa reached the maximum at the end of the experiment.

(2) The $\mathrm{UV}_{254}$, chlorophyll, and $\mathrm{pH}$ of the four microalgae all increased with the culture time, and the maximum increase of chlorophyll ratio of microalgae all appeared in the early stage of the experiment. With the increase of culture time to $10, \mathrm{pH}$ gradually became saturated.

(3) The four microalgae have different removal rules for $\mathrm{Fe}, \mathrm{Mn}$, and $\mathrm{Cu}$, but they can all achieve good removal effects, and the maximum removal rate of $\mathrm{Fe}$ is $54.13 \%$, which appeared on the fourth day of Microcystis aeruginosa treatment group. The maximum removal rate of $\mathrm{Mn}$ was $72.71 \%$, which appeared on the 6th day of Anabaena flos-aquae treatment group.

(4) Microcystis aeruginosa was the dominant species in this experiment, and the best effect was achieved on the $4^{\text {th }}$ day of treatment.

\section{Acknowledgments}

We acknowledge supports from the National Natural Science Foundation of China(41773100), Funding projects for research activities of academic and technological leaders of Anhui Province(2020D239), and the Research Project of Huaibei Mining Group Co. (2021).

\section{Conflict of Interest}

The authors declare no conflict of interest.

\section{References}

1. NGUYEN T., TRAN H., BUI D. Investigation of As, Mn and $\mathrm{Fe}$ fixation inside the aquifer during groundwater exploitation in the experimental system imitated natural conditions. Environmental Geochemistry \& Health. 34 (3), 349, 2012. 
2. GUO Y., ZHANG J., CHEN X. Kinetics and mechanism of $\mathrm{Mn}^{2+}$ removal from groundwater using iron-manganese co-oxide filter film. Water Science and Technology-Water Supply. 16 (7), 1711, 2019.

3. PIRAS F., SANTORO O., PASTORE T. Controlling micropollutants in tertiary municipal wastewater by $\mathrm{O}_{3} / \mathrm{H}_{2} \mathrm{O}_{2}$, granular biofiltration and $\mathrm{UV}_{254} / \mathrm{H}_{2} \mathrm{O}_{2}$ for potable reuse applications. Chemosphere. 239, $124635,2020$.

4. DAS B., HAZARIKA P., SAIKIA G. Removal of iron from groundwater by ash, A systematic study of a traditional method. Journal of Hazardous Materials. 141 (3), 834, 2007.

5. KALAK T., JOANNA D., B Y T. Effective use of elderberry (Sambucus nigra) pomace in biosorption processes of Fe(III) ions. Chemosphere. 246, 125744, 2019.

6. SUN Y., LI X., ZHENG W. Facile synthesis of core-shell phase-transited lysozyme coated magnetic nanoparticle as a novel adsorbent for $\mathrm{Hg}(\mathrm{II})$ removal in aqueous solutions. Journal of Hazardous Materials. 403, 124012, 2021.

7. CHOI J., IM S J., JANG A. Application of volume retarded osmosis - Low pressure membrane hybrid process for recovery of heavy metals in acid mine drainage. Chemosphere. 232 (OCT.), 264, 2019.

8. SRIVASTAVA S., AGRAWAL S.B., MONDAL M.K. A review on progress of heavy metal removal using adsorbents of microbial and plant origin. Environmental Science and Pollution Research. 22 (20), 15386, 2015.

9. URRUTIA C., YAÑEZ-M, JEISON D. Bioremoval of heavy metals from metal mine tailings water using microalgae biomass. Algal Research-Biomass Biofuels and Bioproducts. 43, 101659, 2019.

10. ROSARIO M., CORREA-M, VILLEGAS-P. Uptake of copper from acid mine drainage by the microalgae Nannochloropsis oculata. Environmental Science and Pollution Research. 26 (7), 6311, 2019.

11. WANG Z., LUO Z., YAN C. Arsenic uptake and depuration kinetics in Microcystis aeruginosa under different phosphate regimes. Journal of Hazardous Materials. 276, 393, 2014.

12. BRINZA L., GERAKI K., COJOCARU C. Baltic Fucus vesiculosus as potential bio-sorbent for $\mathrm{Zn}$ removal, Mechanism insight. Chemosphere. 238, 124652, 2020.

13. QIU Y., WANG Z., LIU F. Effect of different kinds of complex iron on the growth of Anabaena flos-aquae. Environmental Technology. 40 (22), 2889, 2019.

14. DENG J., FU D., HU W. Physiological responses and accumulation ability of Microcystis aeruginosa to zinc and cadmium, Implications for bioremediation of heavy metal pollution. Bioresource Technology. 303, 122963, 2020.

15. LING Y., SUN L., WANG S. Cultivation of oleaginous microalga Scenedesmus obliquus coupled with wastewater treatment for enhanced biomass and lipid production. Biochemical Engineering Journal. 148, 162, 2019.

16. WU Y., GUO P., ZHANG X. Effect of microplastics exposure on the photosynthesis system of freshwater algae. Journal of Hazardous Materials. 374, 219, 2019.

17. OK Y S., BHATNAGAR A., HOU D. Advances in algal biochar, Production, characterization and applications. Bioresource Technology. 317, 123982, 2020.
18. MARJAKANGAS J., CHEN C., LAKANIEMI A. Simultaneous nutrient removal and lipid production with Chlorella vulgaris on sterilized and non-sterilized anaerobically pretreated piggery wastewater. Biochemical Engineering Journal. 103, 177, 2015.

19. ZERVEAS S., KYDONAKIS E., MOUTIDIS P. Microalgae strategy in anoxic atmospheres with various $\mathrm{CO}_{2}$ concentrations - Environmental and (astro) biotechnological perspectives. Environmental and Experimental Botany. 187, 104474, 2021.

20. YOOEUN C., SANG H., YOUN-J. Photosynthesis enhancement in four marine microalgal species exposed to expanded polystyrene leachate. Ecotoxicology and Environmental Safety. 189, 109936, 2020.

21. ISLAMI H.R., ASSAREH R. Effect of different iron concentrations on growth, lipid accumulation, and fatty acid profile for biodiesel production from Tetradesmus obliquus. Journal of Applied Phycology. 31 (6), 3421, 2019.

22. HAN F., HUANG J., LI Y. Enhanced lipid productivity of Chlorella pyrenoidosa through the culture strategy of semi-continuous cultivation with nitrogen limitation and $\mathrm{pH}$ control by $\mathrm{CO}_{2}$. Bioresource Technology. $136(0), 418$, 2013.

23. ANDEDEN E.E., OZTURK S., ASLIM B. Effect of alkaline $\mathrm{pH}$ and nitrogen starvation on the triacylglycerol (TAG) content, growth, biochemical composition, and fatty acid profile of Auxenochlorella protothecoides KP7. Journal of Applied Phycology, 33 (1), 211, 2020.

24. CIURLI A., DI BACCIO D., SCARTAZZA A. Influence of zinc and manganese enrichments on growth, biosorption and photosynthetic efficiency of Chlorella $\mathrm{sp}$. Environmental Science and Pollution Research, 28 (7), 8539, 2021.

25. LIU X., CHEN G., TAO Y. Application of effluent from WWTP in cultivation of four microalgae for nutrients removal and lipid production under the supply of $\mathrm{CO}_{2}$. Renewable Energy. 149, 708, 2020.

26. BOYD P., LAW S., WONG C. The decline and fate of an iron-induced subarctic phytoplankton bloom. Nature. 428 (6982), 549, 2004.

27. HUANG Y., WEI C., LIAO Q. Biodegradable branched cationic starch with high $\mathrm{C} / \mathrm{N}$ ratio for Chlorella vulgaris cells concentration: Regulating microalgae flocculation performance by $\mathrm{pH}$. Bioresource Technology. 276, 133, 2019.

28. PACHECO D., ROCHA A.C., PEREIRA L. Microalgae Water Bioremediation: Trends and Hot Topics. Applied Sciences. 10 (5), 1886, 2020.

29. BRINZA L., DRING M.J., GAVRILESCU M. Marine micro and macro algal species as biosorbents for heavy metals. Environmental Enineering and Management Journal. 6 (3), 2007.

30. MONTEIRO C., CASTRO P., MALCATA F. Metal uptake by microalgae, Underlying mechanisms and practical applications. Biotechnology Progress. 28, 299, 2012.

31. ZHOU B., MA J., CHEN F. Mechanisms underlying silicon-dependent metal tolerance in the marine diatom Phaeodactylum tricornutum. Environmental Pollution, 262, 114331, 2020. 